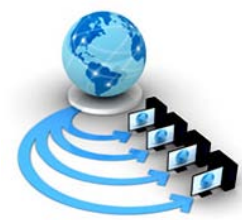

Volume 9, No. 3, May-June 2018

\title{
COMPARATIVE ANALYSIS ON REDUCING ROUTE DISCOVERY LATENCY IN MANET USING DIFFERENT TECHNIQUES
}

\author{
Dilpreet Kaur \\ Student.RIEIT \\ Rayat Group of Institutions, Railmazra \\ Ropar, India
}

\author{
Sheetal Kundra \\ Associate Professor, RIEIT \\ Rayat Group of Institutions, Railmazra \\ Ropar, India
}

\begin{abstract}
MANET is a self-configuring network, in which topology is dynamic. These nodes are struggling to cope with the normal effect of radio communication channels, multi-user interference, multi-path fading etc. The design of an optimum routing protocol for MANET is highly difficult. To determine the connectivity of network organizations, there is a need for an efficient algorithm link scheduling, and routing in such dynamic scenarios, becomes very important. The efficiency of a routing algorithm depends on the proficient and winning route computation. Usually, the shortest path algorithm is a successful method to calculate the optimal way in static networks. But this idea is not possible in MANET platform. There are many factors which can be considered for routing. Multihop paths are used in MANET for interconnecting the nodes. All the nodes are present in the network which are used for path construction for delivering a packet from source to destination node.
\end{abstract}

\section{INTRODUCTION}

A self-configuring network that has dynamic topology consisting of numerous nodes is known as Mobile ad-hoc network. There are some normal effects present in the surroundings that are to be matched by the nodes present within the network. The nodes make efforts to cope up with the radio communication channels, multi-path fading, and such other effects [2]. The mobile ad-hoc network is the network in which no central controller is present and it is the decentralized type of network. In such type of network, mobile node configures with random topology. In the random topology, each node is aware of the nodes which are their adjacent nodes or in their direct range.

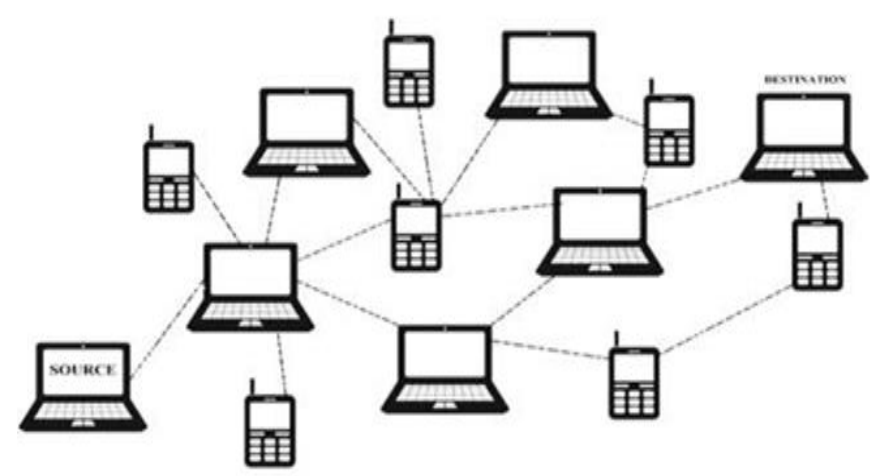

Figure1.MANET Architecture

As illustrated in figure 1, mobile devices, a laptop is configured to form a network. In this type of network, single and multihop communication is possible. In single hop communication when two nodes are a direct range of each and in multihop, communication node can communicate each other indirectly through intermediate nodes.

\section{A. Advantages of MANET}

1) Convenience: These networks being wireless in nature permits users to utilize network assets from approximately any suitable location inside their main networking environment which can be office or home.

2) Mobility: It is observed that with time there is a significant evolution of public wireless networks, which now enable users to access the internet while they are outside their working environments like home or office.

3) Productivity: It describes that when users are connected to a wireless network, they can seamlessly go through their desired task online without any interruption even when they are on the go.

4) Deployment: The deployment of the infrastructure less ad hoc network is not much of arrangement; it requires mobile nodes which can work as source as well as a router.

5) Expandability: The ad-hoc networks are scalable in nature, therefore it can handle the addition of new clients to the network. Whereas in case of a wired network, the addition of new clients would need some extra wiring this will add to the cost.

6) Cost: The hardware required for wireless ad hoc network is quite expensive on the basis of device configurations.

\section{B. Applications of MANET}

The nodes can join or leave the network at any instant in MANET. As there is no central coordinator present in this network, they selfconfigured, and self-organized. These networks 
are easy to deploy anywhere within no time, because deployment cost-effective, and no infrastructure is required. The features of MANET are used by military departments in various applications:

- For commercial usage, the sensor networks are used .the sensor nodes are located in sea dessert and forest for sensing the data and send back to the location.

- $\quad$ Personal LAN gaming, video conferencing are some examples of local communication usage of MANET.

- Old wired LAN is now replaced by PAN (Personal Area Network).

- In a wired network, large infrastructure is required if the base stations or the central controller fails the whole network gets interrupted. Military applications take advantage MANET and used it in the battlefield.

\section{TYPES OF ROUTING PROTOCOL}

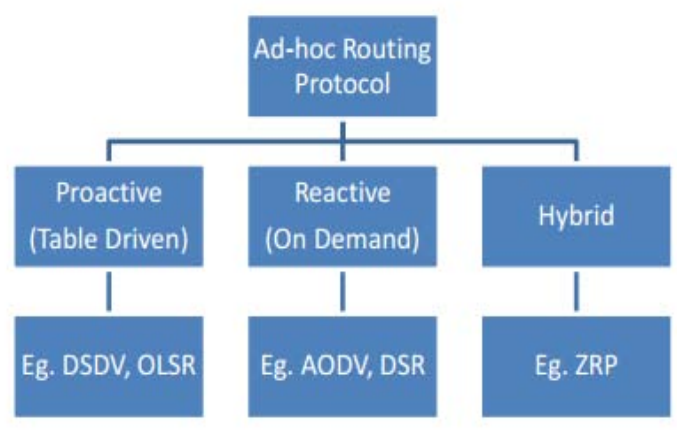

Figure2. Classification of Routing Protocol

There are basically three types of ad-hoc routing protocols which are shown in figure 1.2 are proactive, reactive, hybrid protocols.

\section{A. Proactive Routing Protocol}

Proactive routing protocols are table driven routing protocols. In this, all the nodes have a wireless link with their neighbor nodes at all the time. All information about establishing path is stored in the routing table and constantly get updated which is used to establish the path between source and destination. All the nodes present in the network, maintain and create routing information to every node keep information of an adjacent node which is used during the time of path establishment [4].

\section{A. DSDV: Destination sequence distance vector}

The DSDV is a table-driven routing protocol which is basically based on traditional Bellman-Ford Routing Algorithm along with various enhancements in it. The lists of all the present destinations are available in the routing table that is maintained by each node. This also contains the details related to the sequence number which is assigned to the destination node as well as the number of hops that are required for the packet to reach towards the destination. The static routes are separated from the new routes with the help of sequence number which further avoids the formation of loops. The routing tables are transmitted across the periodic stations towards the immediate neighbors and in case of any changes occurring within the network, the updates are sent to the routing table for providing changes. If there are two sequence numbers for any two routes, the route that has the shortest path will be selected [3, 7]. The multi-path routing is not performed by the DSDV; however, a good quality of shortest path is provided which is reliable enough [8].

Advantages of DSDV: Some of the advantages of DSDV are listed below:

1. Similar to the DSR this algorithm is also very simple.

2. Across the destination sequence number, this protocol is loop-free.

3. Within the route discovery process, there is no latency.

Disadvantages of DSDV: Main Disadvantages of DSDV are:

1. There are no sleeping nodes in the network.

2. Most of the routing information is never used.

\section{B. Reactive Routing Protocol}

In these types of routing protocols, a path is established whenever it required. All the nodes in the network are not active all the time. Nodes get active whenever there is a need for path construction. So that is why this protocol is also known as demand-driven protocols or source initiated on-demand routing protocol. Route discovery is used to find out the shortest path for packets delivery [4].In this process, RREQ packet is broadcast through the network.

\section{A. On-demand distance vector routing protocol (AODV):}

The ad hoc on demand vector is the efficient routing protocol which uses a single source and destination routing. In AODV path establishment protocol source node will flood the route request packets within the network. With the help of route reply packets, the nodes that are present adjacent to the destination will respond back. The source node has various available paths and source select best path with the help of hop count as well as a sequence number. The hop count defined the number of hopes and sequence number defines the path freshness

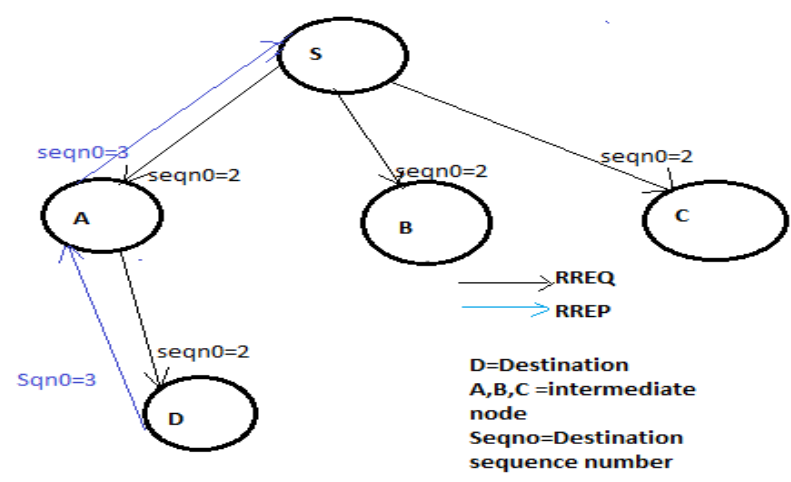

Figure 3: AODV routing protocol

\section{Hybrid Protocol}


This protocol is the combination of both the proactive and reactive routing protocols. These protocols have the properties of both routing protocols, which help to get the best result. In the initial stage, routing is done with some predefined information which is kept on the node and after that source flood route request packets to gather network information. The basic idea is that each node has predefined information of its zone head and nodes which are in the zone, the protocol used to maintain routing information in the network is proactive.

\section{LITERATURE REVIEW}

- Changling Liu et al. [1] proposed in this paper a major issue that is faced by the mobile ad hoc networks routing protocol design. As the network is very importantly utilized in various applications this major challenge is to be resolved. Another important part of the network is the routing method that helps the protocols within the mobile ad hoc networks to communicate with each other. On the basis of the various assumptions made related to the properties of the networks, the design protocols to be used are determined. The characteristics of such various protocols are also explained in this paper.

- While, S.S Tyagi et al. [5] proposed in this paper the various simulation-based comparisons and performance analysis on the various parameters such as PDF, average and to end delay, routing overheads and packet loss. On the basis of three distinct protocols AODV, DSR, and DSDV, the various analysis and investigations have been carried out and ns2 tool has been utilized to do so. Within the category of proactive routing protocol, the DSDV has been selected. However, AODV and DSR fall into the category of reactive routing protocols. There are around a thousand of nodes present within the AODV protocol. However, the DSR design has around two hundred nodes in it. Apart from the packet loss issue, the performance of AODV is better in the case of dense environments. The performance of DSR and AODV is better than the others such as DSDV. There are various merits and demerits with the application of protocols in different scenarios. There are a lot of challenges being faced in the field of ad hoc networks with their growth and developments being proposed at the time.
- AmithKhandakaret.al [6] examined that MANET is a network where nodes are free to move. They can use multiple hop paths to exchange data. Routing protocols are required for timely and efficient delivery of data. In this paper three routing protocol has been compared those are AODV, DSDV, DSR with the various parameters even when there is a various number of nodes present. A stepwise approach on the basis of various assumptions is done within this paper which can also be utilized in the future work.

- Jagdeep Kaur, Rupinder Kaur Gurm et.al [7] described that MANET is a network in which nodes can freely join and leave the network. MANET is decentralized in nature which means it has no any center node to control the network. It is infrastructure less and topology changes frequently which causes a decrease in network performance. To solve this problem, Cuckoo search algorithm is a good technique.CSO is used to find out the best suitable path for packet delivery in MANET. In this paper, AODV and DYMO are implemented on NS2 simulator with or without using CSO algorithm and comparison is done.

- Dr. Umadevi Chezhiyan [8] they explained the importance of the ad-hoc networks which communicate and establish a path between two end nodes. Routing is used for searching and constructing the path between the nodes which are present in the network to deliver the data packets from initiated node to terminal node. A reactive protocol has high performance as compare to proactive protocols. Various merit and demerits have been discussed in this paper and analysis of performance is done. At the end measurement performance analysis is also done in MANET.

- Charu Sharma and Jaspreet Kaur [9] explained that MANET is a network which can be easily deployed. MANET has no central controller so topology changes dynamically. Topology change is a challenging issue in MANET. In this paper, the description of the network methods within the complete network is analyzed within the OPNET simulation with respect to various performance metrics. There are various parameters on the basis of which comparisons are made and the simulator tool is utilized within the OPNET modeler 14.0 in this work.

Table 2.1 summarizes the work done by various researchers related to performance analysis of MANETs routing protocols.

\begin{tabular}{|l|l|l|l|l|}
\hline $\begin{array}{l}\text { Authors name } \\
\text { reference }\end{array}$ & $\begin{array}{l}\text { Protocols } \\
\text { used }\end{array}$ & Simulator & Performance Metrics & Variable Parameters \\
\hline Guntupalli et al. & $\begin{array}{l}\text { DSDV, } \\
\text { DSR, } \\
\text { AODV }\end{array}$ & NS2 & $\begin{array}{l}\text { Average End to End Delay, } \\
\text { Normalized Routing Load, Packet } \\
\text { Delivery Ratio }\end{array}$ & $\begin{array}{l}\text { Number of Nodes, Speed, } \\
\text { Pause time, Transmission } \\
\text { Power }\end{array}$ \\
\hline
\end{tabular}




\begin{tabular}{|c|c|c|c|c|}
\hline Yogesh et al. & AODV, DSR & GLOMOSIM & $\begin{array}{l}\text { Packet Delivery Ratio, End to End } \\
\text { Delay, Normalized routing overhead }\end{array}$ & $\begin{array}{l}\text { Number of nodes, Speed, } \\
\text { Pause time }\end{array}$ \\
\hline Chenna et al & $\begin{array}{l}\text { DSDV, } \\
\text { AODV, } \\
\text { DSR, TORA }\end{array}$ & NS2 & $\begin{array}{l}\text { Throughput, Routing Overhead, } \\
\text { Path Optimality, Packet Loss, } \\
\text { Average delay }\end{array}$ & $\begin{array}{l}\text { Traffic Loads, Movement } \\
\text { Patterns }\end{array}$ \\
\hline $\begin{array}{l}\text { G. Jayakumar et } \\
\text { al. }\end{array}$ & AODV, DSR & NS2 & $\begin{array}{l}\text { Packet Delivery Ratio, Normalized } \\
\text { Routing Load, MAC load and } \\
\text { Average End to End Delay }\end{array}$ & $\begin{array}{l}\text { Number of Sources, Speed, } \\
\text { Pause time }\end{array}$ \\
\hline Birdar et al. & AODV, DSR & NS2 & $\begin{array}{l}\text { Packet Delivery Ratio, Routing } \\
\text { Overhead, Normalized Routing } \\
\text { Overhead and Average End to End } \\
\text { Delay }\end{array}$ & Speed \\
\hline Kapang et al. & $\begin{array}{l}\text { AODV, } \\
\text { DSR, } \\
\text { DSDV }\end{array}$ & NS2 & $\begin{array}{l}\text { Packet Delivery Ratio, Average End to } \\
\text { End Delay and Routing Overhead }\end{array}$ & Pause Time \\
\hline $\begin{array}{l}\text { Vijayalaskhmi et } \\
\text { al. }\end{array}$ & $\begin{array}{l}\text { DSDV, } \\
\text { AODV }\end{array}$ & NS2 & $\begin{array}{l}\text { Packet Delivery Fraction, Average } \\
\text { End-to-End Delay, Throughput }\end{array}$ & $\begin{array}{l}\text { Number of Nodes, Speed, } \\
\text { Time }\end{array}$ \\
\hline Shaily et al & $\begin{array}{l}\text { AODV, } \\
\text { DSR, } \\
\text { ZRP }\end{array}$ & QualNet & $\begin{array}{l}\text { TTL based Hop Count, Packet } \\
\text { Delivery Ratio }\end{array}$ & Pause Time \\
\hline
\end{tabular}

\section{CONCLUSION}

MANET is a self-controlling network. Nodes can easily join and leave the network. Topology changes very frequently in MANET. MANET has various challenges like security, routing, energy consumption etc. A comparative analysis of different routing is explained. A number of researchers have been done to find the solution of challenges in MANET.

\section{REFERENCES}

[1] C. Liu, J. Kaiser, "A Survey of Mobile Ad Hoc Network Routing Protocols". Network IEEE, Vol. 6, 2009, pp. 136.

[2] Navneet Kaur, Amandeep Verma," State of the Art Techniques of Routing Protocols for Mobile Adhoc Network " International Journals of Advanced Research in Computer Science and Software Engineering ISSN: 2277128X (Volume-7, Issue 6) June 2017 pg 55-58

[3] S.A. Ade1\& P.A. Tijare, "Performance Comparison of AODV, DSDV, OLSR and DSR Routing Protocols in MANET”, International Journal of Information Technology and Knowledge Management, Vol. 2, No. 2, Dec. 2010, pp. 545-548

[4] S. Mohseni, R. Hassan, A. Patel, and R. Razali, "Comparative Review Study of Reactive and Proactive Routing
Protocols in MANETs", 4th IEEE International Conference on Digital Ecosystems and Technologies 2010 IEEE, Apr. 2010, pp.- 304-309.

[5] S.S. Tyagi, R.K. Chauhan, "Performance analysis of Proactive and Reactive routing protocols for ad hoc networks", International Journal of computer applications, Vol. 1 No.-14, 2010, pp. 27-30

[6] AmithKhandakar, "Step by Step Procedural Comparison of DSR, AODV, and DSDV Routing protocol", 2012 4th International Conference on Computer Engineering and Technology (ICCET 2012) IPCSIT vol.40 (2012) (C) (2012) IACSIT Press, Singapore pg 36-40

[7] Jagdeep Kaur, Rupinder Kaur Gurm, "Performance Analysis of AODV and DYMO Routing Protocols in MANETs Using Cuckoo Search Optimization", International Journal of Advanced Research in Computer Science and Management Studies Volume 2, Issue 8, August 2014 pg. 236-247

[8] Dr. Umadevi Chezhiyan, "Measurement-Based Analysis of Reactive Protocols in MANET", International Journal of Advanced research in computer science and software engineering Vol.3, Issue 8, August 2013 pg 1-4

[9] Charu Sharma and Jaspreet Kaur, "Simulative Analysis of AODV Routing Protocol of MANET Using OPNET Modeler 14.0", International Research Journal of Engineering and Technology (IRJET) e-ISSN: 2395 -0056 Volume: 02 Issue: 03 | June-2015 pg 140-143 